\title{
Prevalence of Stress and Coping Mechanism Among Staff Nurses of Intensive Care Unit in a Selected Hospital
}

\author{
Md. Golam Kibria \\ Department of Nursing, East West Nursing College, Dhaka, Bangladesh \\ Email address: \\ kibrianurse@gmail.com \\ To cite this article: \\ Md. Golam Kibria. Prevalence of Stress and Coping Mechanism Among Staff Nurses of Intensive Care Unit in a Selected Hospital. \\ International Journal of Neurosurgery. Vol. 2, No. 1, 2018, pp. 8-12. doi: 10.11648/j.ijn.20180201.12
}

Received: March 29, 2018; Accepted: April 18, 2018; Published: May 10, 2018

\begin{abstract}
Background: Nursing is a highly stressful occupation, and nurses have job-related stressors. There are limited data regarding stress among nurses of intensive care unit in Bangladeshi hospitals. Objective: This study aimed to identify the prevalence of stress among staff nurses working in ICU and factors influencing stress in the past 12 months. Methods: A descriptive cross sectional study was conducted among 50 Staff Nurse of intensive care unit in Square Hospital Ltd. from $1^{\text {st }}$ September, 2012 to $30^{\text {th }}$ January, 2013. Data were collected by face to face interview using semi-structured questionnaire. Results: Majority of nurses (90\%) had experienced stress. Most of nurses (72\%) had experienced back pain as physical stress. Majority of nurses (64\%) had experienced boredom as psychological stress. Most of nurses (62\%) had experienced common mistakes or errors during work. 74\% nurses used prayers and $88 \%$ nurses used sharing problems with others in coping stress. Majority $(86 \%)$ of nurses were having diploma in nursing. Most of nurses $(68 \%)$ had been working experience of more than three years. $100 \%$ nurses feel much stressed when one nurse give care to the more than one patient. There is no association between stress and work stressors (work experiences, ratio of nurse to patient, working relationship with doctors, and working relationship with nurse manager). Conclusion: High stressful among intensive care unit (ICU) nurses in Square Hospital Ltd. had been identified and impact on the health and well-being of critical care nurses due to stress. Large scales should be conducted for study.
\end{abstract}

Keywords: Stress, Coping Mechanism, ICU Nurses

\section{Introduction}

Stress is a major concern in the nursing profession. Stress among nurses is the result of exposure to a combination of working environment and personal factors. Stress occurs when nurses try to manage patient's nursing care within the scope of nursing. Critical care nurses practice in a complex assessment, high intensity therapies and continuous nursing vigilance [1]. The change in Health care delivery has also created new nursing roles and responsibilities and has also contributed to the source of stress [2]. Nurses constantly experience a stressful environment because of the complex nature of patient's health problems requiring an extensive use of very sophisticated technology [3]. Nurses not only have to cope with the sophisticated technology but also regularly face ethical dilemmas concerning issues of patient care management. Stress also occurs when there is a constant desire to achieve only the best.

\subsection{Types of Work Stressors}

Some researchers have indicated issues related to death and dying of patients nursed closely with the hope of recovering as fully stressful for critical care nurses. Decision making is another factor that is a concern for critical care nurses. Previous research has also indicated that the source of stress among ICU nurses is more organizational in nature. Organizational stressors could be physical, psychological and social in nature. [4] Several researchers have described ICU as a stressful environment found that ICU environment itself creates stress for nurses [3, 5]. [Studies have also shown that high level of stress can affect the competence and job performance of nurses identified the ICU environment and the psychological impact of working in an ICU as two factors contributing to the stress experienced by ICU nurses. However, a study done in Netherlands on 521 nurses did not agree with the idea that the work environment in ICU is more stressful 
than a non ICU [6]. Nurses working in environments where verbal and physical aggression is prevalent are more likely to experience the effects of stress. The other determinants causing the stress in ICU nurses could be due to increased job demand, nursing shortage, overload of work, lack of social support from colleagues, a lot of paperwork and high expectations from the superior, organization and patients $[7,8]$.

\subsection{Effect of Work Stressors}

Stress has also been found to be associated with mood changes which include tension, anxiety, fatigue and depression [9]. Effect of burnout can range from a degree of dysfunction to exhaustion and loss of control [10]. Response to stress can be divided into three categories i.e. mental, physical and emotional. Emotional and mental responses to stress has been linked to outbursts of anger, unnecessary worries and frequent mood changes whereas physical stress is associated with cardiac disorders, ulcer and skin rashes [11]. Previous studies on stress among nurses have identified positive relationships between work stresses, mental distress and high incidences of stress [12]. Little is known about the prevalence of stress and the factors influencing stress among the nurses in ICU in Bangladesh. This study thus aims to investigate the prevalence of stress among the critical care nurses, factors influencing the stress and to examine the relationship between stressors and nurses.

\section{Methodology}

\subsection{Research Design}

A descriptive cross sectional study was utilized to conduct this study.

\subsection{Study Area and Study Period}

This study was conducted among staff nurse of intensive care unit in Square Hospital Ltd. from $1^{\text {st }}$ September, 2012 to $30^{\text {th }}$ January, 2013.

\subsection{Sample Size and Sampling Techniques}

A total of 50 staff nurses were selected using purposive sampling technique.

The inclusive criteria used in the recruitment of the samples are that nurses must be registered with Bangladesh Nursing Council.

\subsection{Data Collection Tools}

Data were collected by face to face interview by interviewing questionnaire.

\subsection{Data Processing and Analysis}

Data were coded and entered into SPSS (Statistical Package for Social Sciences) for descriptive analysis. Data were described by frequencies and percentages. Chi-square was performed to investigate the relationship between factors influencing stress and socio-demographic data.

\section{Results}

\subsection{Description of Samples}

Table 1: Mean age of nurses $(2.54 \pm 0.542)$, the majority $(50 \%)$ were in the age group of $26-30$ years, majority (98\%) were females, and majority of the nurses $(68 \%)$ have working experience of more than three years. In relation to marital status, $(48 \%)$ of the respondents were married and (52\%) were unmarried. Majority $(86 \%)$ of nurses were having diploma in nursing, while ( $8 \%$ ) having B.Sc. in nursing, and $(6 \%)$ having master of public health. Based on less having B.Sc. in nursing and less having master of public health qualified nurse, nurses may not have a strong foundation and knowledge regarding to critical care nursing.

Table 1. Demographic characteristics of nurses.

\begin{tabular}{llll}
\hline Characteristics & No. $(\mathbf{n}=\mathbf{5 0})$ & $\mathbf{\%}$ & Mean \pm S.D \\
\hline Age: & 24 & 48 & \\
22 -25 years & 25 & 50 & $2.54 \pm 0.542$ \\
26-30 years & 1 & 2 & \\
>30 years & & & \\
Gender: & 4 & 8 & \\
Male & 46 & 92 & \\
Female & & & \\
Education: & 43 & 86 & \\
Diploma in Nursing & 4 & 8 & \\
B.Sc in Nursing & 3 & 6 & \\
Master of Public Health & & 48 \\
Marital status: & 24 & 52 \\
Married & 26 & 38 \\
Unmarried & & 62 \\
Working experience: & 19 & \\
<3 years & 31 & \\
>3 years & &
\end{tabular}

Table 2: There are found to be living with families 27 (54\%), living on their own accounted for $3(6 \%)$, living with friends $1(2 \%)$, and living with the colleagues $19(38 \%)$.

Table 2. Distribution of respondents by living.

\begin{tabular}{lll}
\hline Living & Frequency & Percentage (\%) \\
\hline Living with families & 27 & 54.0 \\
Own accounted & 3 & 6.0 \\
Living with friends & 1 & 2.0 \\
Living with collegues & 19 & 38.0 \\
\hline
\end{tabular}

\subsection{Prevalence of Stress}

From the total number of 50 nurses, $45(90 \%)$ of the nurses said that they had experienced physical stress, psychological stress, and changed in behavior during work in the past 12 months through the stress inventory.

Stress Inventory

Table 3: Majority of the nurses 36 (72\%) experienced back pain. $35(70 \%)$ nurses experienced headache followed by abdominal pain $10(20 \%)$ and chest pain $11(22 \%) .12(24 \%)$ nurses experienced viral infection, experienced insomnia $16 \%$, weight loss $32 \%$, ulcer $12 \%$, skin rashes $22 \%$. However, cardiac disorder was experienced by only a minority (4\%) of nurses. In relation to psychological stress, majority $32(64 \%)$ was experienced boredom. 22 (44\%) of nurses were anxiety, 
experienced depression (42\%), frustration (34\%), poor concentration $(32 \%)$, and hasty decision making (40\%). The four changes in behavior of nurses were identified. Common mistakes or error $(62 \%)$, conflict with others $(34 \%)$, aggressiveness (22\%), and absenteeism (12\%).

Table 3. Distribution of respondents experience to stress $(n=50)$.

\begin{tabular}{lll}
\hline Stress & Frequency & Percentage (\%) \\
\hline Physical & & \\
Back pain & 36 & $72 \%$ \\
Headache & 35 & $70 \%$ \\
Weight loss & 16 & $32 \%$ \\
Viral infection & 12 & $24 \%$ \\
Chest pain & 11 & $22 \%$ \\
Abdominal pain & 10 & $20 \%$ \\
Skin rashes & 11 & $22 \%$ \\
Insomnia & 8 & $16 \%$ \\
Cardiac disorder & 2 & $4 \%$ \\
Psychological & & \\
Boredom & 32 & $64 \%$ \\
Anxiety & 22 & $44 \%$ \\
Depression & 21 & $42 \%$ \\
Hasty decision making & 20 & $40 \%$ \\
Frustration & 17 & $34 \%$ \\
Poor concentration & 16 & $32 \%$ \\
Changes in behavior during work & & \\
Common mistakes or errors & 31 & $62 \%$ \\
Conflict with others & 17 & $34 \%$ \\
Aggressiveness & 11 & $22 \%$ \\
Absenteeism & 6 & $12 \%$ \\
\hline * & &
\end{tabular}

${ }^{*}$ Multiple responses

\subsection{Experienced Stress During Nursing Care to the Patient}

Table 4: A total of $23(46 \%)$ nurses indicated they feel stressful when nursing a critically ill patient compared to 27 (54\%) when nursing patients who require resuscitation. Nurses-patient ratio was identified as a stress factor by 100 percent of the nurses. However, nurses who were given only one patient to care finds it less stressful compared to nursing to more than one patient. The majority $(94 \%)$ indicated that being in a safe environment with sophisticated machines as less stressful to handle as operating and fixing the machines requires a lot of knowledge and patience. Eighty eight (88\%) nurses find it comfortable working with doctors and ninety $(90 \%)$ nurses find it comfortable working in the presence of their nurse manager.

Table 4. Distribution of respondents by experienced stress during nursing care to the patient $(n=50)$.

\begin{tabular}{lll}
\hline Work stressors & No. $(\mathbf{n}=\mathbf{5 0})$ & \% \\
\hline Critically ill patient & & \\
Critically ill patient & 23 & 46 \\
Critically ill patient who requires resuscitation & 27 & 54 \\
Ratio nurses to patient & & \\
Ratio of 1 nurse to more than 1 patient & 39 & 78 \\
Ratio of 1 nurse to 1 patient & 11 & 22 \\
Relationship with doctors & & \\
Comfortable & 44 & 88 \\
Uncomfortable & 6 & 12 \\
Relationship with nurse manager & & \\
Comfortable & 45 & 90 \\
Uncomfortable & 5 & 10 \\
Sophisticated machine & & 94 \\
Safe environment & 47 & 6 \\
Unsafe environment & 3 & \\
\hline
\end{tabular}

Table 5: There is no association between stress and work stressors (work experiences, ratio of nurse to patient, working relationship with doctors, and working relationship with nurse manager) $(\mathrm{p}>0.05)$

Table 5. Relationship between stress and work Stressors (study variables) $(n=50)$.

\begin{tabular}{|c|c|c|c|c|c|}
\hline \multirow{2}{*}{ Work stressors } & \multicolumn{2}{|l|}{ Stress } & \multirow{2}{*}{ Total } & \multirow{2}{*}{$\begin{array}{l}\text { Significance of } \\
\text { association }\end{array}$} & \multirow{2}{*}{ p-value } \\
\hline & Yes & No & & & \\
\hline \multicolumn{6}{|l|}{ Work experiences } \\
\hline$<$ than 3 years & $18(99.0 \%)$ & $01(1.0 \%)$ & 19 & $\chi^{2}=3.40$ & $\mathrm{p}>0.05$ \\
\hline$>$ than 3 years & $26(83.9 \%)$ & $05(16.1 \%)$ & 31 & $\mathrm{p}=.065$ & \\
\hline \multicolumn{6}{|l|}{ Ratio of nurse to patient } \\
\hline 1 nurse: more than 1 patient & $35(89.7 \%)$ & $4(10.3 \%)$ & 39 & $\chi^{2}=0.013$ & $\mathrm{p}>0.05$ \\
\hline 1 nurse: 1 patient & $10(90.9 \%)$ & $1(9.1 \%)$ & 11 & $\mathrm{p}=0.901$ & \\
\hline \multicolumn{6}{|c|}{ Working relationship with doctors } \\
\hline Comfortable & $40(90.9 \%)$ & $4(9.1 \%)$ & 44 & $\chi^{2}=0.337$ & $\mathrm{p}>0.05$ \\
\hline uncomfortable & $5(83.3 \%)$ & $1(16.7 \%)$ & 06 & $\mathrm{p}=0.562$ & \\
\hline \multicolumn{6}{|c|}{ Working relationship with nurse manager } \\
\hline Comfortable & $41(91.1 \%)$ & $4(8.9 \%)$ & 45 & $\chi^{2}=0.617$ & $\mathrm{p}>0.05$ \\
\hline Uncomfortable & $4(80 \%)$ & $1(20 \%)$ & 05 & $\mathrm{p}=0.432$ & \\
\hline
\end{tabular}

\subsection{Coping Mechanisms}

Table 4: The three coping mechanisms adopted by ICU nurses were identified. Prayers (74\%) and sharing problems with other $(88 \%)$ were the common method used in coping stress. Some $(34 \%)$ of nurses used to relieve stress by taking rest between work.
Table 4. Distribution of respondents by their coping mechanism to relieve stress $(n=50)$.

\begin{tabular}{lll}
\hline Coping mechanism during work & Frequency & Percentage \\
\hline Feelings and sharing problems with others & 44 & $88 \%$ \\
Prayers & 37 & $74 \%$ \\
Taking rest between work & 17 & $34 \%$ \\
\hline
\end{tabular}




\section{Discussion}

Findings of this study indicated that the prevalence of stress among nurses in ICU, Square Hospital Ltd. is $90 \%$ which is high. Three categories of stress in this study are physical, psychological, and changes in behavior related interested findings. The common physical stress experienced by nurses in ICU were headache, viral infection, back pain, insomnia, weight loss, abdominal pain, chest pain, weight gain, cardiac disorder, ulcer, and skin rashes. The psychological stress experienced by the nurses is slightly high which consisted of fatigue, anxiety, poor concentration, boredom, hasty decision making, irritability, guilty, loss of interest, depression, and frustration. However, the type of changes in behavior experienced was common errors at work, aggressiveness, absenteeism, and having conflict with colleagues. Stress at work did not indulge any of the ICU nurses to be involved in drugs and alcohol as strong spirituality and religious background may have prevented the nurses from doing so [13].

In this study, only $8 \%$ nurses had completed BSc in Nursing and only $3 \%$ nurses had completed master of public health. Lack of knowledge among ICU nurses was also identified as a main indicator of stress among ICU Nurses [14]. Findings also indicated that the majority (46\%) of the nurses in this study experienced stress when nursing critically ill patients that nurses feel stressful. BSc in Nursing and master of public health or master in Nursing degree completed nurses in ICU is necessary for working in a specialized unit like the ICU as it demands a high level of knowledge and skill in handling critically ill patients [15].

Nurses working in ICU are more often confirmed with life sustaining treatment decisions and ethical issues concerning issues of patient care management. Death and dying are frequently encountered and this poses a high level of stress for the nurses working in ICU [16, 17]. Study findings among ICU nurses in Hong Kong also reported the causes of stress being nursing critically ill patients, shortage of nurses, increasing workload and interpersonal relationship among the staff [18].

Nurses were found to have more than one patient under their care. Nurses find it very stressful when nursing two or three patients under their care. Shortage of nurses is the main factor causing nurses to care for two to three patients. The inability to meet the needs of patients is affected by the nurse's workload and ultimately patients and the nurse's suffer [19]. Nursing stress ultimately can have an impact on the patient and compromise patient care [20]. Despite heavy workload being a frequently reported stressor, it is suggested that some stress may be necessary for optimum functioning. But, of course, heavy workload may lead to other negative consequences [21].

Maintaining a professional relationship among colleagues during work is important as it results in a harmonious working environment. In this study, $88 \%$ nurses work comfortably with doctors and $99 \%$ nurses have good relationship with nurse manager. Teamwork and collaboration need to be strong or else nurses will find difficulties in speaking about problems. Poor professional relationship may cause a stressful working environment. Therefore, specialized knowledge and competency are required in ordered for nurses to communicate and collaborate effectively, which will improve patient care [22].

This study indicated that $94 \%$ nurses created safe environment with fixing and operative machines as less stressful, which requires a lot of knowledge and patience. Stress can also be alleviated by the availability of coping resources such as social support. Nurses in this study were found to have prayer $(74 \%)$, sharing problems with other $(88 \%)$, and taking rest between works (34\%) as coping strategies. However, nurses should be taught the appropriate coping skills. Stress inoculation training could be implemented to prevent total burnout among ICU nurses. Painful problem solving as the most frequent coping strategy being used by nurses in other countries [21, 23, 24].

\section{Conclusion}

This study was important implications for critical care nursing practice and administration. Critical care nurses work in an environment that is high stressful due to the increased responsibility in the management of patient care. Stress can be reduced resulting from increasing high level of knowledge $\&$ skilled nurses. More graduated nurse should be increased. Encouraging ICU nurses to take up post basic course for diploma nurses and Master in nursing courses should not be only opened by government but also by private in Bangladesh. Hospital authority can also take steps for nurses that stress will be reduced.

\section{References}

[1] Norbeck, J. S. Perceived job stress, job satisfaction, and Psychological symptoms in Critical care nursing. Research in nursing \& health1985; 8(3): 253-259.

[2] Erlen, J. \& Sereika, S. M. Critical Care Nurses, Ethical Decision-Making, and Stress. J Adv Nurse. 1997; 26(5): 953961.

[3] Robinson, J. A. \& Lewis, D. J. Coping with ICU work-related stressors: A Study. Critical Care Nurse1990; 10(5):80-88.

[4] Duquette, A., Sandhu, B. K., Beaudet, L. Factors Related to Nursing Burnout: A Review of Empirical Knowledge. Issues in mental Health Nursing 1994; 15:337-358.

[5] Youngner, S., Jackson, D. L. \& Allen, M. Staff Attitudes towards the Care of the Critically Ill in the Medical Intensive Care Unit1979; 7(2):35-40.

[6] Boumans, N. P. G. \& Landeweerd, J. A. Working in an Intensive or Non-Intensive Unit: Does It Make a Difference? Heart \& Lung. 1994; 23:71-79.

[7] Janssen, P. P. M., deJonge, J., Bakker, A. B. Specific Determinants of Intrinsic Work Motivation, Burnout and Turnover intentions: A Study among Nurses. J Adv Nurse 1999; 29:1360- 1369. 
[8] Bakker, A. B., Killmer, C. H., Siegriest, J., Schaufeli, W. B. 2000. Effort-Reward Imbalance and Burnout among Nurses, J Adv Nurs. 31:884- 891.

[9] Cox, T. \& Ferguson, E. Individual Differences, Stress and Coping. In. Cooper, C. L. \& Payne, R. Personality \& Stress: Individual Differences in the Stress Process. eds, Wiley, Chichester 1991; pp 7-30.

[10] Tavares, M. Burnout in AIDS Care. Professional Nurse 1994; 12:24-27.

[11] Dunham, J. 1984. Stress New York: Nichols Publishing Co.

[12] Tyler, P. A. \& Cushway, D. Stress, Coping and Mental WellBeing in Hospital Nurses. Stress Medicine 1992; 8:91-98.

[13] Milazzo, N. Stress levels of ICU verses and non-ICU nurses, DCCN1988; 7:52-58.

[14] Steffen, A. Social psychological for nursing. England: Jones and Barlett publishers international; 1980.

[15] Kelly, J. G. \& Cross, D. G. Stress coping behaviors and recommendations for intensive care and medical surgical ward registered nurses. Research Nursing Health 1985; 8:831-838.

[16] Sawatzky, J. A. Stress in critical care nurses; Actual and perceived. Heart \& Lung 1996; 22:534-541.
[17] Bartz, C. \& Maloney, J. P. Burnout among intensive care nurses. Research in Nursing and Health 1986; 9:53-147.

[18] Lau, R \& Chan, S. The stressors of nurses in the intensive care unit in Hong Kong. Hong Kong Nur J. 1995; 69:17-24.

[19] Coghan, J. A. An analysis of stress in intensive care units in Melbourne. Aust J Adv Nur. 1984; 1:27-31.

[20] Gently, W. Foster, Froehling, S. Psychologic responses to situational stress in intensive and nonintensive nursing. Heart \& lung 1972; 1:793-796.

[21] Payne, K. The relationship of hardiness and social support to student appraisal of stress in an initial clinical nursing situation. J Nur Edu 2001; 33(3):396.

[22] Cottrell, S. Occupational stress and job satisfaction in mental health Nursing, United Kingdom. Aust J Adv Nur. 1984; 62:55-59.

[23] Healy, C. M. \& McKay, M. F. Nursing stress; the effects of coping strategies and job satisfaction in a sample of Australia nurses. Aust J Adv Nur. 2000; 31(3):681-688.

[24] O'Brien, T. B. \& Delongis, A. The interactional content of problem, emotion, and relationship focused coping; the role of the big five personality factors. J Pers. 1996; 64:755-813. 